\title{
Efeito do grau de bipartição escrotal sobre a vascularização arterial do escroto de caprinos nativos do Estado do Plauí
}

Mônica Marcos ALMEIDA ${ }^{1}$

Maria Acelina Martins de

CARVALHO $^{2}$

Antonio Augusto

Nascimento MACHADO

JUNIOR ${ }^{3}$

Dario Abbud RIGHI

Fabiana Galtarossa XAVIER ${ }^{4}$

Aírton Mendes CONDE

JÚNIOR ${ }^{1}$

Pedro Primo BOMBONATO 5

\section{Correspondência para:}

Profa. Dra. Maria Acelina Martins de Carvalho

Departamento de Morfofisiologia Veterinária do Centro de Ciências Agrárias - Universidade Federal do Piaui Campus da Socopo S/N, 64049-550 Teresina/PI, (86) 3215-5748, carvalhomam@uol.com.br

Recebido para publicação: 28/07/2006 Aprovado para publicação: 17/08/2007

\author{
1 - Programa de Pós-Graduação em Ciência Animal, Centro de Ciências Agrárias \\ da Universidade Federal do Piauí, Teresina-PI \\ 2 - Departamento de Morfofisiologia Veterinária do Centro de Ciências Agrárias \\ da Universidade Federal do Piauí, Teresina-PI \\ 3 - Campus Profa Cinobelina Elvas, Universidade Federal do Piauí, Bom Jesus-PI \\ 4 - Departamento de Patologia da Faculdade de Medicina Veterinária e Zootecnia \\ da Universidade de São Paulo, São Paulo-SP \\ 5 - Departamento de Cirurgia da Faculdade de Medicina Veterinária e Zootecnia \\ da Universidade de São Paulo, São Paulo-SP
}

\section{Resumo}

Palavras-chave:

Caprino.

Avaliou-se a vascularização arterial do escroto em caprinos com vários graus de divisão escrotal. Foram utilizados 30 animais, distribuídos Escroto. em três grupos: I - animais que apresentavam escroto único e aqueles com divisão até extremidade caudada dos testículos; II - animais com divisão escrotal até $50 \%$ do comprimento dos testículos; III - caprinos com divisão escrotal acima de 50\% do comprimento testicular. Os caprinos foram sacrificados e, no Laboratório de Anatomia Animal da Universidade Federal do Piauí, realizadas as técnicas de repleção, corrosão ou dissecação, para estudo das artérias escrotais. A artéria escrotal origina-se freqüentemente $(95 \%)$ da artéria pudenda externa, eventualmente $(3,3 \%)$ da epigástrica caudal superficial, ou ainda originase como um ramo cranial da artéria epigástrica caudal superficial e um ramo caudal da artéria pudenda externa $(1,7 \%)$. Na região dorsal do septo do escroto emite dois a três ramos primários, que fornecem os ramos secundários e terminais, os quais distribuem-se, indistintamente, nas faces cranial e caudal do escroto e, ocasionalmente, no septo do órgão. $\mathrm{O}$ número de ramos terminais não apresenta diferença em relação à configuração escrotal, porém a região correspondente à divisão escroto, conta com maior quantidade desses ramos nos animais que apresentam essa característica mais acentuada.

\section{Introdução}

A caprinocultura tem um papel de grande relevância econômica e social no Brasil, sobretudo na Região Nordeste, onde se constitui uma boa alternativa para produção de leite, carne e couro. O rebanho nativo, apesar de mostrar-se bem adaptado às condições de altas temperaturas desta região, em certos períodos do ano, o potencial produtivo desses animais apresenta-se limitado, necessitando-se, portanto, de estudos que possibilitem a seleção de animais que sejam mais resistentes a essas condições.

O sucesso da produção animal depende de vários aspectos, dos quais o reprodutivo constitui um dos principais, e está relacionado, principalmente, à interação genótipo/meio ambiente. ${ }^{1}$

A relação de vários fatores induz a adaptações morfofisiológicas nos animais, que contribuem para modificar sua eficiência reprodutiva. Dentre elas, podemos citar uma divisão externa do escroto, observada em caprinos de regiões áridas e semi-áridas do Leste da África ${ }^{2}$ e, posteriormente, em caprinos criados na região Nordeste do 
Brasil, sendo denominada "bolsa escrotal bipartida ${ }^{3}$. Esta característica, amplia a superfície de cada testículo exposta ao meio ambiente, propiciando melhor dissipação de calor e possibilitando um aumento na qualidade do sêmen e na eficiência reprodutiva desses animais em relação àqueles que não a possuem. ${ }^{4,5}$

A bipartição escrotal é encontrada em grandes proporções no caprino criado no Nordeste brasileiro, podendo ser considerada uma adaptação para equilibrar a produção espermática em altas temperaturas ambientais, em função da maior aeração e troca de calor. ${ }^{3}$

Além dessa característica, o escroto apresenta eficientes mecanismos que atuam no processo de termorregulação. Alguns destes mecanismos incluem o fluxo sangüíneo superficial, as trocas calóricas o arranjo dos vasos sangüíneos e a sudorese. ${ }^{6}$ Colaborando ainda com este mecanismo termorregulatório observa-se a relação especial entre artéria testicular e o plexo pampiniforme, proporcionando devido a sua disposição, um eficiente mecanismo de contracorrente, pelo qual o sangue arterial que entra nos testículos é resfriado pelo venoso que flui em direção a cavidade abdominal. A temperatura do sangue da artéria testicular sofre uma queda em seu percurso do anel inguinal interno até a superfície dos testículos enquanto que a temperatura sangüínea nas veias aumenta progressivamente dos testículos no sentido do anel inguinal externo. A proximidade das artérias e veias à superfície testicular tende a aumentar a perda direta de calor dos testículos.

O objetivo deste trabalho foi estudar a vascularização arterial do escroto, observando a origem, trajeto e distribuição desses vasos em caprinos com diferentes graus de divisão escrotal, uma vez que não existem dados sobre estes aspectos em caprinos com o escroto bipartido.

\section{Material e Método}

Foram utilizados 30 reprodutores caprinos, sem raça definida, oriundos das micro-regiões de Campo Maior e Teresina, no Estado do Piauí, divididos em três grupos de dez animais, considerando a configuração escrotal, grupo I - animais com escroto simples; grupo II - animais que apresentavam escroto bipartido até $50 \%$ do comprimento testicular e, grupo III - animais cujo escroto apresentava bipartição superior a $50 \%$ do comprimento testicular.

Os animais foram sacrificados com dose letal de anestésico geral intravenoso e, para a identificação dos vasos arteriais escrotais, as artérias pudendas externas foram canuladas e injetadas com solução fisiológica para a limpeza do sistema vascular do escroto. Nas artérias escrotais, em cada antímero, foi injetado $3 \mathrm{ml}$ de Latex BiCentrifugado (Latex Altamira Ltda) corado em vermelho. As peças foram congeladas por 24 horas para coagulação da substância plástica e, em seguida, foram fixadas por injeção de solução aquosa de formol a 10\%, preenchendo-se ainda a cavidade vaginal com algodão, simulando a presença do testículo, facilitando assim a dissecação das artérias escrotais.

Após a dissecação os vasos escrotais foram esquematizados, fotografados e analisados quanto ao número de ramos terminais nas faces caudal, cranial e no septo escrotal.

Para a análise estatística dos dados obtidos foi utilizada a Anova de uma via, seguido do teste post-hoc de Duncan. Em todos os experimentos, a probabilidade de $\mathrm{p}<0,05$ foi assumida como um indicador de significância estatística. Dados são apresentados como média \pm desvio-padrão.

\section{Resultados}

A artéria escrotal, nos caprinos estudados, apresentou origem predominantemente, da artéria pudenda externa, ventralmente aos linfonodos escrotais (Figura 1), em 20 casos do grupo I $(100 \%), 19$ casos do grupo II $(95,00 \%)$ e 18 casos do grupo III $(90,00 \%)$.

Em dois casos (antímeros esquerdos 


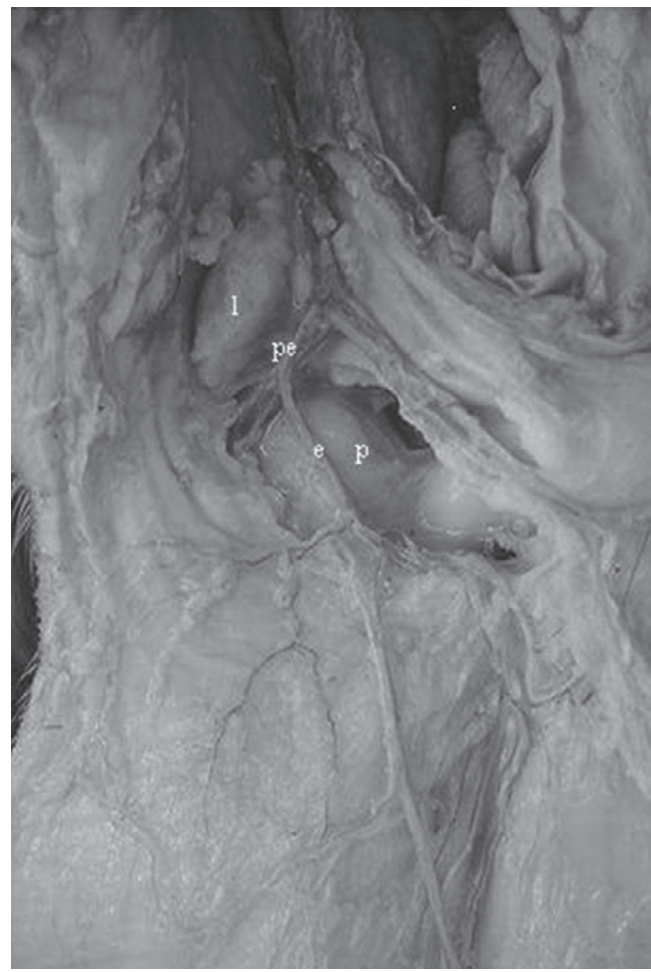

Figura 1 - Fotomacrografia da superfície interna do escroto de caprino, antímero direito. Observase a origem da artéria escrotal (e) a partir da artéria pudenda externa (pe), ventralmente ao linfonodo escrotal (l) e lateralmente ao pênis (p)

$-10,00 \%$ ), pertencentes a animais do grupo III, a artéria escrotal teve origem na artéria epigástrica caudal superficial. Observou-se em um caso $(5,00 \%)$, no antímero direito de um exemplar do grupo II, a ocorrência de duas artérias escrotais, uma cranial, originária da artéria epigástrica caudal superficial e outra caudal, originária da artéria pudenda externa.

A artéria escrotal do caprino apresentou-se inicialmente como um tronco que passa lateralmente ao pênis. $\mathrm{Na}$ região dorsal do septo escrotal, emite de dois a três ramos primários que seguem em direção ventral originando ramos secundários e terminais para as faces cranial e caudal do escroto, bem como para o septo escrotal.

Observou-se que a divisão da artéria escrotal em dois ramos primários ocorreu em 17 casos do grupo I (85,00\%) e 16 $(80,00 \%)$ tanto no grupo II quanto no grupo III. Com menor predominância, três casos
$(15,00 \%)$ do grupo I e III, e dois casos do grupo II (10,00\%), essa artéria dividiu-se em três ramos primários.

Em cada grupo foram observados antímeros contendo um ramo terminal dirigido ao septo escrotal, sendo 5,00 \% nos grupos I e II. No grupo III surgiram dois casos possuindo dois ramos terminais destinados ao referido septo $(10,00 \%)$. Em alguns casos, foram originados ramos, antes da divisão principal da artéria escrotal. No grupo I foram observados seis casos $(30,00$ $\%$ ) com ramos destinados à face cranial do escroto, seis casos $(30,00 \%)$ à face caudal e dois $(10,00 \%)$ com ramos para ambas as faces. No grupo II havia dois casos $(10,00$ $\%$ ) com ramos dirigidos à face cranial, três $(15,00 \%)$ para a face caudal e um caso $(5,00$ $\%)$ com ramos para ambas as faces. No grupo III, dois casos $(10,00 \%)$ apresentavam ramos destinados à face cranial, três casos $(15,00 \%)$ possuíam ramos para a face caudal e em um caso $(5,00 \%)$ os ramos irrigavam as duas faces.

Foram verificadas anastomoses entre a artéria escrotal e um ramo da artéria epigástrica caudal superficial em dois casos do grupo II $(10,00 \%)$ e em um caso do grupo III (5,00 \%). Em relação ao número de ramos terminais distribuídos nas faces cranial e caudal do escroto, não foi encontrado diferença significativa entre os grupos estudados, assim como entre os antímeros. $\mathrm{O}$ número de ramos terminais compreendidos na região da divisão escrotal diferiu entre os grupos (Tabela 1) sendo mais vascularizado os escrotos do grupo III, seguidos dos grupos II e I, consecutivamente.

\section{Discussão}

O arranjo dos vasos sangüíneos no escroto, assim como, o fluxo sangüíneo superficial, representam alguns dos eficientes mecanismos de termorregulação do órgão. ${ }^{6}$ A artéria escrotal, nos caprinos estudados, apresentou origem predominantemente, da artéria pudenda externa, ventralmente aos linfonodos escrotais, sendo estas 
Tabela 1 - Valores individuais, médias e desvios-padrão do número de ramos arteriais terminais distribuídos na região correspondente à divisão escrotal de caprinos nativos do Estado do Piauí

\begin{tabular}{|c|c|c|c|c|}
\hline \multirow[b]{2}{*}{ OBSERVAÇÃO } & \multirow[b]{2}{*}{ ANTÍMERO } & \multicolumn{3}{|c|}{ Grupos $^{1}$} \\
\hline & & I & II & III \\
\hline 01 & Esquerdo & 3 & 7 & 7 \\
\hline 01 & Direito & 2 & 6 & 9 \\
\hline 02 & Esquerdo & 5 & 6 & 11 \\
\hline 02 & Direito & 2 & 6 & 9 \\
\hline 03 & Esquerdo & 0 & 4 & 9 \\
\hline 03 & Direito & 0 & 4 & 12 \\
\hline 04 & Esquerdo & 0 & 5 & 8 \\
\hline 04 & Direito & 0 & 5 & 9 \\
\hline 05 & Esquerdo & 2 & 3 & 6 \\
\hline 05 & Direito & 0 & 5 & 4 \\
\hline 06 & Esquerdo & 1 & 8 & 11 \\
\hline 06 & Direito & 2 & 6 & 9 \\
\hline 07 & Esquerdo & 2 & 4 & 11 \\
\hline 07 & Direito & 1 & 4 & 9 \\
\hline 08 & Esquerdo & 3 & 6 & 10 \\
\hline 08 & Direito & 1 & 4 & 10 \\
\hline 09 & Esquerdo & 0 & 6 & 10 \\
\hline 09 & Direito & 0 & 4 & 7 \\
\hline 10 & Esquerdo & 6 & 1 & 13 \\
\hline \multirow[t]{2}{*}{10} & Direito & 4 & 4 & 11 \\
\hline & Esquerdo & $2 \pm 2,10$ & $5 \pm 2,41^{\#}$ & $10 \pm 2,12^{*}$ \\
\hline \multirow[t]{2}{*}{ Média $\pm \mathrm{DP}$} & Direito & $1 \pm 1,32$ & $5 \pm 0,95^{\#}$ & $9 \pm 2,18^{*}$ \\
\hline & TOTAL & $2 \pm 1,78$ & $5 \pm 1,55^{\#}$ & $9 \pm 2,12^{*}$ \\
\hline
\end{tabular}

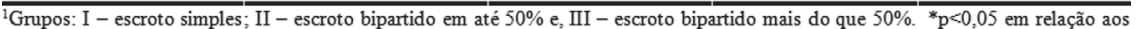
grupos II e I; \#p<0,05 em relação ao grupo I. Anova seguido do teste de Duncan

observações correspondentes às feitas para a maioria dos animais domésticos ${ }^{8,9,10}$ referentemente aos ramos escrotais craniais ou ramo escrotal ventral, designado para os mamíferos domésticos ${ }^{11}$, bovinos $^{6,12}$, quando afirmam que a artéria pudenda externa se distribui essencialmente no escroto. Nos pequenos ruminantes, estes últimos autores, citam que os vasos escrotais são originados do tronco pudendo-epigástrico, podendo também emergirem da artéria ilíaca externa, o que difere da maioria dos nossos dados em caprinos. Os ramos escrotais craniais, nos animais domésticos ${ }^{8}$, são oriundos da artéria pudenda externa, enquanto, os ramos escrotais caudais são provenientes da artéria pudenda interna. Segundo relatos ${ }^{13}$, a origem de ramos escrotais, nos ruminantes, ocorre a partir da artéria pudenda externa, corroborando com este trabalho (Figura 1).

Nesta pesquisa foi observado, em um caso no antímero direito de um exemplar do grupo II, a ocorrência de duas artérias escrotais, uma cranial, originária da artéria epigástrica caudal superficial e outra caudal, originária da artéria pudenda externa. Este achado se assemelha em parte com o que foi verificado em 90,9\% dos bovinos estudados $^{6}$, entretanto os ramos escrotais cranial e caudal, nesses animais originavamse da artéria pudenda externa.

A artéria escrotal no caprino apresentou-se inicialmente como um tronco que passa lateralmente ao pênis, semelhante ao descrito para os animais domésticos ${ }^{11}$, porém difere do observado para ruminantes e eqüinos ${ }^{10}$, nos quais esta artéria passa 
medialmente aos testículos e externamente à túnica vaginal. Ainda, conforme já salientado, na região dorsal do septo escrotal, emite dois a três ramos primários que seguem em direção ventral originando ramos secundários e terminais para as faces cranial e caudal do escroto, bem como para o septo, semelhantemente ao que foi descrito no zebu ${ }^{6}$, denominando os ramos primários, como craniais e caudais, e os secundários como colaterais.

Observamos, ainda que houve uma diminuição na divisão da artéria escrotal em dois ramos secundários, quando comparamos os animais com escroto simples e bipartido, sendo estas percentagens superiores em relação à encontrada no bovino zebu. ${ }^{6}$

No bovino zebu o ramo escrotal cranial irriga a maior parte da parede cranial do escroto e do septo escrotal, e seus ramos colaterais e terminais distribuem-se superficialmente na pele e túnica dartos, e mais profundamente, nas fáscias cremastérica e espermática externa. O ramo escrotal caudal irriga a maior parte caudal do escroto e do septo escrotal, com posição e distribuição análogas às do ramo escrotal cranial. ${ }^{6}$ Este arranjo difere em parte dos dados desta pesquisa, em todos os grupos de caprinos estudados, pois os ramos primários e secundários distribuem-se indistintamente nas faces cranial, caudal e no septo do escroto, podendo os ramos terminais na face cranial originar-se de ramos primários ou secundários da face caudal, o que ocorre também em relação aos ramos na face caudal. Também não foi observado nos animais pesquisados, a distribuição arterial nas fáscias cremastérica e espermática externa, considerando o escroto, como constituído pela pele e túnica Dartos.

Notou-se ainda que em todos os grupos foram observados antímeros contendo um ramo terminal dirigido ao septo escrotal, no entanto, Bohórques Mahecha e Godinho ${ }^{6}$ não quantificaram os ramos destinados à irrigação do septo escrotal, mas informaram que esta se faz por ramos oriundos dos vasos escrotais craniais e caudais.

Em alguns casos, verificou-se que foram originados ramos, antes da divisão principal da artéria escrotal, o que não foi encontrada na literatura consultada. Anastomoses, entre a artéria escrotal e um ramo da artéria epigástrica caudal superficial, foram encontradas nos animais com diferentes graus de bipartição escrotal. De outra forma, no zebuíno ${ }^{6}$, foram observadas as anastomoses entre os ramos colaterais e terminais do ramo escrotal cranial e os colaterais e terminais do ramo escrotal caudal.

Em relação ao número de ramos terminais, distribuídos nas faces cranial e caudal do escroto, não foi encontrada diferença significativa entre os grupos estudados, assim como entre os antímeros. O número de ramos terminais compreendidos na região da divisão escrotal diferiu entre os grupos, sendo mais vascularizado nos animais com maior bipartição escrotal. Esta diferença na concentração de ramos terminais entre os grupos decorre das variações na área desta região, o que não significa dizer que o grupo que possui a maior vascularização é também o mais irrigado.

Como se observa, a maioria dos resultados referentes à vascularização do escroto não puderam ser confrontados com as informações da literatura consultada, uma vez que, os autores descrevem o suprimento arterial do escroto nos animais, de maneira genérica, informando na maioria das vezes apenas a origem das artérias destinadas à irrigação do órgão. Apenas o trabalho em bovinos zebu ${ }^{6}$, fornece informações mais específicas sobre a distribuição e o comportamento das artérias que participam da irrigação do escroto e dos outros envoltórios testiculares, agrupando esses vasos em sistemas arteriais superficial e profundo. $\mathrm{O}$ sistema superficial apresenta ramos derivados da artéria pudenda externa, os quais se ramificam na pele do escroto, túnica dartos e fáscia espermática externa. Estes resultados coincidem com os obtidos 
nos animais desta pesquisa, com exceção da vascularização da fáscia espermática externa, pois não foi identificada a distribuição vascular na mesma.

\section{Conclusões}

Com base no exposto, conclui-se que a artéria escrotal origina-se freqüentemente $(95,00 \%)$ da artéria pudenda externa, eventualmente $(3,3 \%)$ da epigástrica caudal superficial, ou ainda, como um ramo cranial da artéria epigástrica caudal superficial e um ramo caudal da artéria pudenda externa (1,7 \%). $\mathrm{Na}$ região dorsal do septo do escroto emite dois a três ramos primários, que fornecem os ramos secundários e terminais, os quais distribuem-se, indistintamente, nas faces cranial e caudal do escroto e, ocasionalmente, no septo do órgão. $\mathrm{O}$ número de ramos terminais não apresenta diferença em relação à morfologia escrotal, porém a região correspondente à bipartição escroto, conta com maior quantidade desses ramos nos caprinos que apresentam essa característica mais acentuada.

Apoio: CNPq: 478080/03-4; CNPq/PADCT: 620145/04-8

\title{
Effect of the scrotal division degrees on the arterial supply distribution of native goats from the Piaui State
}

\begin{abstract}
The present study was design to investigate the arterial distribution of goat's scrotum with several degrees of scrotum division. We used 30 animals divided in 3 groups of 10 animals each as follow: group I: animals with simple scrotum; II - animals with $50 \%$ of scrotum division; III - animals with more than $50 \%$ of scrotum division. The goats were sacrificed under deep anaesthesia and the techniques for evaluate the arterial distribution were performed at the Laboratory of animal anatomy of the Federal University of Piaui. The origin of the scrotum artery was mainly from the pudenda artery (95\%), follows by the superficial caudal ephigastric artery $(3,3 \%)$, or had your origin as one cranial branch of the superficial caudal ephigastric artery and one caudal branches of the extern pudenda artery $(1,7 \%)$. The dorsal region of scrotal septum seed two or three primary branches that provide the secondary and terminals branches, which had indiscriminate distribution into the cranial and caudal faces of the scrotum, and occasionally at the septum. The number of the terminal branches doesn't have show any difference with the scrotum configuration, however the region that corresponds to the scrotum division had more number of these branches at the animals with the greatest scrotal division.
\end{abstract}

\section{Referências}

1 SANTOS, D. O.; SIMPLÍCIO, A. A.; MACHADO, R. Características escroto-testiculares e do ejaculado em bodes mestiços submetidos à insulação escrotal. Arquivo Brasileiro de Medicina Veterinária e Zootecnia, v. 50, n. 3, p. 287-291, 1998.

2 ROBERTSHAW, D. Concepts in animal adaptation: thermoregulation of the goat. In: INTERNATIONAL CONFERENCE ON GOAT PRODUCTION AND
Key words:

Goat.

Scrotum.

Arterial distribuition
DISEASE, 3., 1982, Tucson. Proceedings... Seoltsdale: Dairy Goat Journal, 1982. p. 395-397.

3 NUNES, J. F.; SILVA, A. E. D. F.; RIERA, S. G.; LIMA, F. A. M. e PONCE DE LEON, F. A. Preliminary report on observed differences in goat semen characteristics based on scroat morphology. In: REUNION INTERNACIONALE DE REPRODUCTION DES RUMINANTS EN ZONE TROPICAL, 20., 1983, Guadelupe. Proceedings... Paris: INRA, 1984. p. 251-264. (Les colloques de I'INRA; 20). 
4 NUNES, J. F.; RIERA, G. S.; SILVA, A. E. F. D.; PONCE DE LEON, F. A.; LIMA, F. A. M. Características espermáticas de caprinos moxotó de acordo com a morfologia escrotal. Sobral: EMBRAPA/CNPCaprinos, 1983. 11 p. (Circular técnica, 6).

5 SILVA, A. E. D. F.; NUNES, J. F.; MELO, F. A. Influência da morfologia escrotal nas características do sêmen e seus efeitos na fertilidade de caprinos. A Hora Veterinária, ano 5, n. 29, p. 66-69, 1986.

6 BOHÓRQUES MAHECHA, G. A.; GODINHO, H. P. Irrigação arterial do escroto de zebu, Bos indicus, Arquivo Brasileiro de Medicina Veterinária e Zootecnia, v. 44 , n. 2, p. 121-127, 1992.

7 HAFEZ, E. S. E. (Ed.). Reprodução animal. 6. ed. São Paulo: Manole, 1995. 582 p.

8 BERG, R. Anatomía topográfica y aplicada de los animales domésticos. Madrid: Editorial AC, 1978. $415 \mathrm{p}$.

9 NICKEL, R.; SCHUMMER, A.; SEIFERLE, E. The viscera of the domestic mammals. 2. ed. Berlim: Verlag Paul Parey, 1979. 401 p.

$10 \mathrm{ABEL}, \mathrm{R}$. E. Anatomia veterinaria aplicada. 2. ed. Zaragoza, España: Acribia, 1988. 315 p.

11 BARONE, R. Anatomie comparée des mammifères domestiques: angiologie. Paris: Vigot, 1996. v. 5, p. 904.

12 SCHWARZE, E.; SCHRÖDER, L. Compendio de anatomia veterinaria: aparato circulatorio y piel. Zaragoza, España: Acribia, 1972. 247 p.

13 GODINHO, H. P.; CARDOSO, F. M.; NASCIMENTO, J. F. Anatomia dos ruminantes domésticos. Belo Horizonte: Departamento de Morfologia. Instituto de Ciências Biológicas da UFMG, 1987. $415 \mathrm{p}$. 